\title{
Experiencias cognitivas en la interpretación de un mapa dasimétrico de densidad de población para la región Pátzcuaro Zirahuén, Michoacán, México
}

\author{
Jesús Abraham Navarro Moreno*
}

Recibido 28 de mayo de 2018; aceptado 30 de septiembre de 2018

\begin{abstract}
This paper belongs to the communicative paradigm of Cartography. Its objective is to reveal cognitive experiences during the interpretation of a dasymetric map. The problem is posed to pre-grade students, who are close to finish their bachelor's studies in Geography and aim to increase their cartographic skills. Various tests are conducted around five types of experiences recorded in a semi-structured interview. Within the results it is noted that the participants tend to privilege less thoroughness in the resulting map, this is demonstrated through the inspection of their appreciations and their identification efficiency; nevertheless, the method leaves in them assertive messages of its qualities.
\end{abstract}

Key words: Cognitive experiences, thematic cartography, map interpretation, dasymetric map.

\section{Resumen}

Este trabajo se inscribe dentro del paradigma comunicativo de la Cartografía. Su objetivo es revelar experiencias cognitivas durante la interpretación de un mapa dasimétrico. El problema es planteado a estudiantes de nivel superior, cercanos a terminar sus estudios de Geografía, que pretenden incrementar sus habilidades cartográficas. Se realizan diversas pruebas en torno a cinco tipos de experiencias registradas en una entrevista semiestructurada. Dentro de los resultados se destaca que los participantes

* Colegio de Geografía, Facultad de Filosofía y Letras, Universidad Nacional Autónoma de México, Ciudad de México, México, correo electrónico: a.navarro@comunidad.unam.mx 
son tendientes a privilegiar menor minuciosidad en el mapa resultante, ello se demuestra a través de la inspección de sus apreciaciones y la eficacia de identificación; no obstante, el método deja en ellos mensajes asertivos de sus cualidades.

Palabras clave: Experiencias cognitivas, cartografía temática, interpretación de mapas, método dasimétrico.

\section{Resumo}

Este trabalho está inserido dentro do paradigma comunicativo da Cartografia. Seu objetivo é revelar experiências cognitivas durante a interpretação de um mapa dasimétrico. O problema é colocado a estudantes de nível superior, próximos a terminar seus estudos de Geografia, que pretendem incrementar suas habilidades cartográficas. Se realizam diversas provas em torno de cinco tipos de experiências registradas em uma entrevista semi-estruturada. Dentro dos resultados se destaca que os participantes são tendenciosos a privilegiar menor minuciosidade no mapa resultante, isso se demonstra através da inspeção de suas apreciações e eficácia de identificação; não obstante, o método deixa mensagens assertivas de sua qualidade.

Palavras chave: Experiências cognitivas, cartografia temática, interpretação de mapas, método dasimétrico.

\section{Introducción}

El cartografiado dasimétrico ha sido del interés de numerosas investigaciones alrededor del mundo. Se trata de un método que ha buscado brindar información más detallada del espacio geográfico, auxiliándose de información complementaria que aumenta, a su vez, la complejidad en la lectura, no sólo por el cambio de perspectiva en la presentación del fenómeno, sino por la particularidad que puede ser alcanzada en las clasificaciones cuantitativas.

Diversas investigaciones recientes se han enfocado en mostrar rutas metodológicas para la obtención del modelo propuesto y su aproximación estadística a la realidad; ejemplo de ello, son las aportaciones realizadas por Eicher y Brewer (2001), Mennis y Hultgren (2006), Tapp (2010), Sleeter (2013) o Neves, et al. (2017).

No obstante, el presente trabajo vira la perspectiva hacia un usuario de la información y trata de indagar en las experiencias cognitivas de un perfil específico: estudiantes de nivel superior que manifiestan interés en incrementar sus habilidades cartográficas. Plantea que las experiencias cognitivas en la interpretación de un mapa dasimétrico, reflejarán que existen preferencias por modelaciones y diseños que contribuyen, en la mente de estos intérpretes, a obtener una imagen más cercana de la dinámica del proceso en el espacio geográfico representado; asimismo, por medio de 
la lectura del mapa, emitirán diversos juicios acerca del método, obteniendo una noción de éste que los llevará a reflexionar en su utilidad. Estas expresiones empíricas serán prueba de que el método emite mensajes asertivos de sus cualidades desde que se conoce por primera vez.

El objetivo de este trabajo es revelar diversas experiencias durante la interpretación de un mapa que emplee este método. De esta manera, se desea contribuir a la investigación cartográfica bajo una perspectiva cognitiva que ayude a evaluar qué tan apropiado es el método dasimétrico para su aprehensión por parte de este perfil de usuario específico bajo estudio. Se trata de una investigación de corte cualitativo, donde tanto el método cartográfico, como los propios sujetos, son objeto de investigación.

La temática de modelación del mapa dasimétrico refiere a la densidad de población, que es frecuente en el estudio del método; todo ello se aplica sobre la región Pátzcuaro Zirahuén en Michoacán, México, debido a que en su espacio presenta coberturas del suelo que han sido analizadas en diversos estudios del método dasimétrico.

\section{Los vínculos de la Cartografía con las experiencias cognitivas}

En Cartografía, el concepto relativo a la cognición o "lo cognitivo" ha sido vinculado a la obtención de una imagen del espacio geográfico derivada de la lectura de mapas. Estas nociones quedan plasmadas en los textos de Lynch (1960) referentes a los mapas mentales, o de Jameson (1991), quien advierte que la cartografía cognitiva es la forma en que un individuo se genera una idea acerca del mundo social que lo circunda. Bajo estos argumentos, el enfoque cognitivo de la cartografía queda asociado de manera estrecha a los posicionamientos conceptuales de la Geografía de la Percepción.

No obstante, si se asume que dicho concepto refiere a toda facultad de un ser vivo para procesar información a partir de lo que ha percibido, sus experiencias y diversas evaluaciones que le permiten asimilar una información que recibe, entonces la cognición, en materia cartográfica, puede considerar una perspectiva más amplia que contribuye al estudio de los mapas; en este sentido, la lectura cartográfica realizada por un intérprete no sólo hace que éste adquiera una idea del espacio geográfico, sino de la propia representación que le proporcionó la información. Montello (2002) advierte que muchos cartógrafos, indudablemente, han reconocido que los mapas contribuyen a forjar una visión del mundo, y que, incluso, pueden haber entendido que este quehacer incluye la toma de decisiones durante el diseño de los mapas.

Estas reflexiones en torno a la importancia de los criterios de confección y diseño y su impacto en los mapas como instrumentos de cognición, tiene tradición en Cartografía. Puede citarse, como ejemplo, a Eckert (1961) cuando refiere la propiedad de la adecuación de los mapas para un propósito; así también, están las proposiciones 
de Robinson et al. (1987), DiBiase (1990) o MacEachren (1994) vinculadas al mapa como un instrumento de comunicación, y los razonamientos aducidos por Joly (1979), Wood (1991) o Suavita y Flórez (1992), donde se advierte la importancia de la lectura e interpretación de los mapas.

\section{Obtención del mapa dasimétrico de la región Pátzcuaro Zirahuén}

\section{Materiales fundamentales}

En este trabajo se utilizó la técnica de las variables relacionadas para la obtención del mapa dasimétrico, compilándose tres informaciones fundamentales. La primera de ellas se refiere a los datos de población, para la cual se tomaron los Principales Resultados por Localidad (ITER), pertenecientes al Censo General de Población y Vivienda 2010, realizado por el Instituto Nacional de Estadística y Geografía (INEGI); esta información consiste en un conjunto amplio de indicadores de población y vivienda a nivel localidad de todo el país, y será la que se tome como referencia para comprobar la aproximación de las modelaciones propuestas.

La segunda información recabada es la división político-administrativa de los territorios de Erongarícuaro, Huiramba, Lagunillas, Pátzcuaro, Quiroga, Salvador Escalante y Tzintzuntzan, que conforman la región Pátzcuaro Zirahuén en Michoacán (CGAP, 2016). A fin de corresponder con la información estadística anterior, se recurrió al Marco Geoestadístico Nacional del INEGI en su versión 2010, que brinda un sistema único y de carácter nacional, donde se referencia la información estadística de los censos y encuestas, vinculada con los lugares geográficos correspondientes. Particularmente, se hizo uso de las Áreas Geoestadísticas Municipales (AGEM) que contienen la extensión territorial integrada de cada uno de los municipios que conforman la división política de las entidades federativas de los Estados Unidos Mexicanos, y están definidos por los límites geoestadísticos (Figura 1).

El último elemento necesario para la generación del mapa dasimétrico es la información auxiliar de contraste; esta información permitirá transitar de los datos básicos originales, con los que se podría hacer un mapa coroplético, ${ }^{1}$ a un mapa donde se distingan zonas detalladas de densidad de población. En este sentido, se utilizó la información de la cartografía del INEGI relativa al Conjunto de Datos Vectoriales de

1 Se reconoce que, desde el posicionamiento soviético y europeo en general, los mapas estadísticos son llamados cartogramas (Raisz, 1948) y no mapas coropléticos. El cartograma, desde el posicionamiento de la cartografía estadounidense, se refiere al tipo de representación que modifica el tamaño y forma de los territorios en función de su valor estadístico, lo que genera anamorfosis. En todo caso, ambas perspectivas (cartograma o mapa coroplético) coinciden en la representación de datos relativizados, no absolutos; puede considerarse, por consiguiente, que el uso de uno u otro término estará asociado con la terminología asumida por la escuela cartográfica. En esta investigación se asumirá el término "mapa coroplético" y sus derivaciones, a fin de corresponder con la mayoría de la literatura generada sobre este tema. 
Uso del Suelo y Vegetación, escala 1:250 000 - Serie V. En el año 2013, se editó la carta E14-1 Morelia, que es referida en esta investigación.

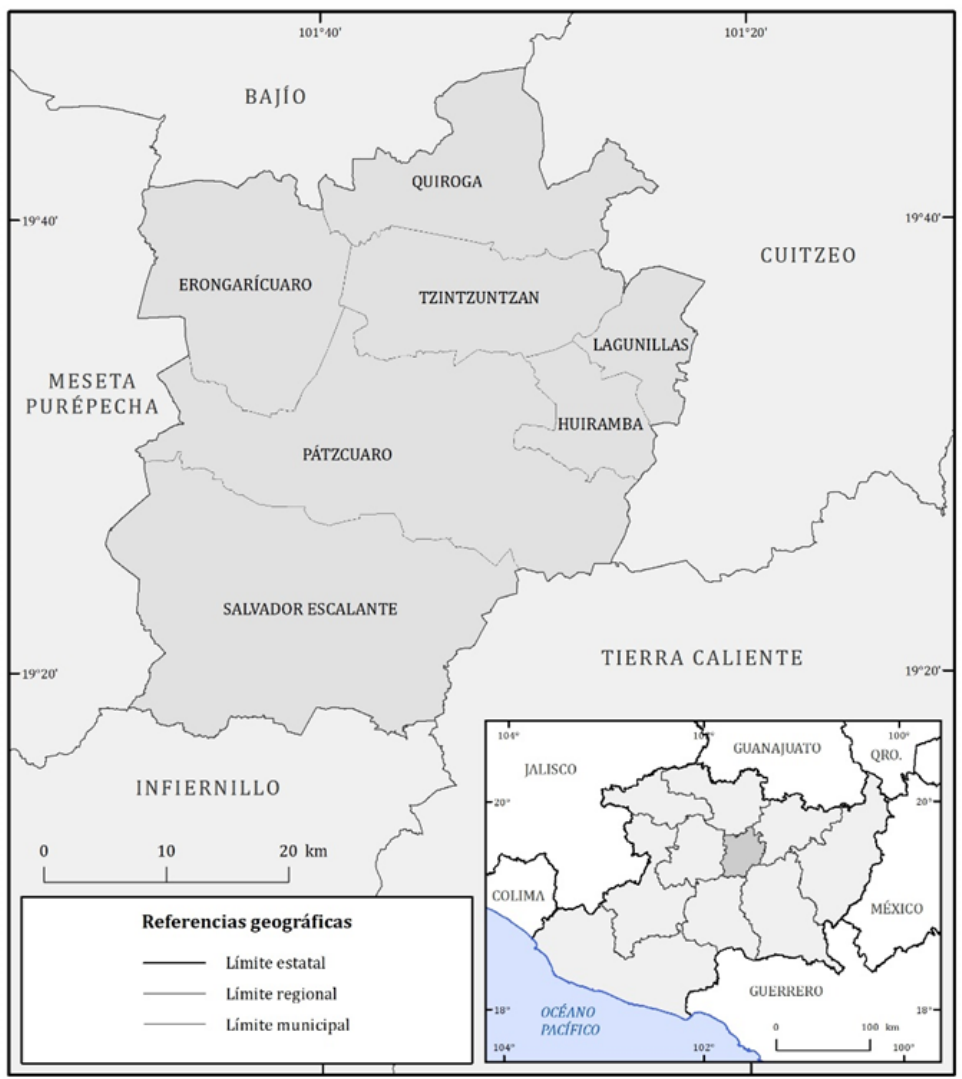

Figura 1. Localización geográfica y conformación territorial de la región Pátzcuaro Zirahuén, Michoacán, México.

Fuente: elaborado sobre la base de INEGI, 2010b; CGAP, 2016.

Para la preparación de la base de datos final del presente trabajo, la información de áreas urbanas fue modificada de la cartografía original 1:250 000. Dichos polígonos se sustituyeron por los indicados como áreas urbanas del Marco Geoestadístico del INEGI en su versión 2013, correspondiente con el año de edición de la carta E14-1, esto con la finalidad de obtener una cobertura más actual del área que ocupan los espacios urbanos dado su comportamiento dinámico. La base de datos resultante fue depurada por criterios del área mínima cartografiable de $1 \mathrm{~mm}^{2} \mathrm{a}$ escala 1:250 000 . 


\section{Metodología}

El mapa dasimétrico propuesto se fundamenta en la intersección de la información citada, considerando que la cobertura de suelo debe ser clasificada por el campo "Entidad"; lo que significa un primer nivel de agregación que establece los grandes tipos de cobertura (Figura 2).

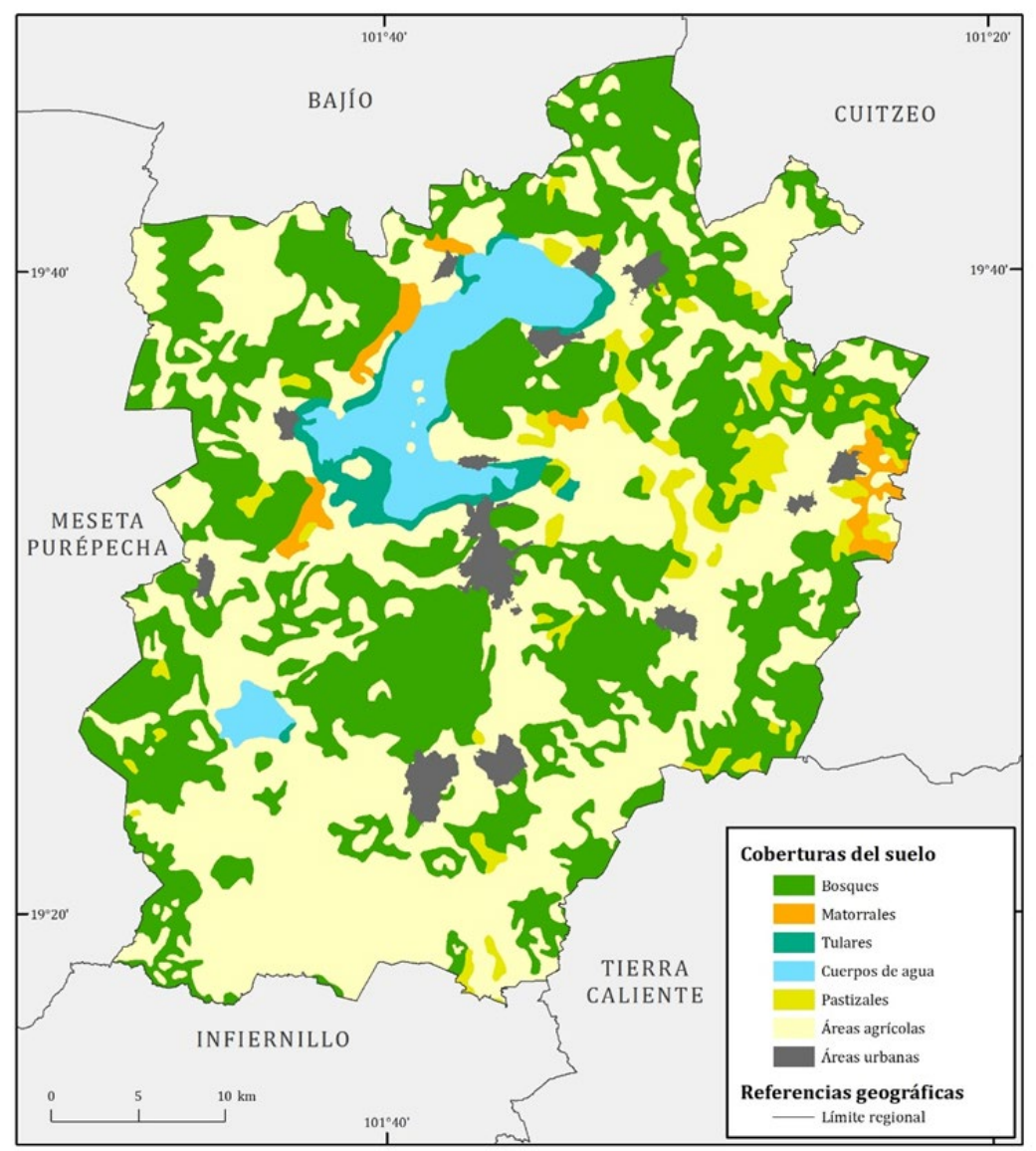

Figura 2. Vegetación y uso del suelo en la región Pátzcuaro Zirahuén.

Fuente: elaborado sobre la base de INEGI, 2010b; INEGI, 2013a; INEGI, 2013b; CGAP, 2016.

Esta información se intersecta con los límites municipales, con la finalidad de considerar diferentes políticas de ocupación de suelo, ya que cada municipio en México puede administrar su territorio y organizar a la población que vive en él. 
Finalmente, los polígonos resultantes adquieren la información de la cantidad de habitantes proveniente del Censo General de Población y Vivienda; así, se establece una sumatoria de habitantes en las localidades que están emplazadas sobre un mismo polígono, pudiendo obtener la densidad de población con las áreas de los polígonos subyacentes.

Con base en la aplicación de las consideraciones metodológicas, se generó un archivo vectorial con 420 polígonos dentro de la zona de estudio, donde el más alto valor de densidad de población registrado fue de $12312 \mathrm{hab} / \mathrm{km}^{2}$ y los más bajos fueron los que el método reveló como espacios deshabitados. Ante este gran número de datos y realidades, cobra relevancia la interpretación y uso de la información cuantitativa generada.

\section{Estrategia metodológica para la obtención de las experiencias cognitivas}

Este trabajo pretende la captura de las experiencias cognitivas, a la vez que proyecta conseguir un acercamiento entre las teorías inscritas y la realidad, objeto de estudio por medio del razonamiento inductivo. Las investigaciones cualitativas se han usado para indagar las actitudes y reacciones de un grupo específico frente a un tema de interés y/o producto; en este caso, el tema de interés cartográfico es la interacción de un perfil de usuario con el método dasimétrico y el producto bajo inspección es el propio mapa dasimétrico.

Comparte fundamentos metodológicos con los estudios de caso, toda vez que registran situaciones conductuales de las personas involucradas, donde el conocimiento más profundo de sus razonamientos contribuye al desarrollo de la teoría (ya sea corroborándola o enriqueciéndola) y se puede obtener la transferibilidad a otros casos (Martínez, 2006).

Bajo estas bases, se conformaron distintos grupos de personas dispuestas a registrar su experiencia cognitiva con el método dasimétrico. En estos grupos se contó con un moderador, quien introdujo el tema a través de nociones básicas que dieran marco a la existencia del método en Cartografía; asimismo, solventó cuestionamientos particulares, encuadró momentos específicos para responder preguntas y mostró la información complementaria necesaria para realizar el ejercicio.

Dentro de la dinámica fue implementada la realización de una entrevista en su forma semiestructurada; las respuestas fueron escritas con el objetivo de contar con un registro físico de las experiencias cognitivas. La entrevista contuvo reactivos cerrados, de selección de opciones a nivel cualitativo y abiertos para efectuar operaciones algebraicas o expresar opiniones del método; así también, pudo ser contestada paulatinamente siguiendo el guion del moderador, aunque con posibilidades para aclarar términos, respetar raciocinios individuales y reducir formalismos, tal como es recomendado por Díaz-Bravo et al. (2013); todo ello, con el fin de obtener la máxima fiabilidad en las respuestas, según las características de esta técnica. 
Los participantes registraron sus experiencias cognitivas en esta entrevista, las cuales se clasificaron en las cinco categorías siguientes y cuyos cuestionamientos específicos se detallarán en el desarrollo de cada una:

- Eficacia en la identificación de signos cartográficos en diferentes clasificaciones

- Selección del mapa dasimétrico de densidad de población y sus características

- Obtención de información con la variable relacionada

- Perspectiva de uso del método dasimétrico

- Reflexiones en torno al método dasimétrico.

\section{Perfil de los participantes}

Se contó con la participación de 33 personas en total, de las cuales $48.5 \%$ correspondieron al género femenino y $51.5 \%$ al género masculino. Una característica importante fue la de ser estudiantes de último año de Licenciatura en Geografía, ello otorga a los entrevistados una relativa experiencia en la lectura de los mapas.

Asimismo, debían declarar tener interés en la Cartografía con el fin de asegurar un ejercicio cognitivo más confiable; esto se consiguió mediante la selección de estudiantes inscritos en asignaturas optativas de temática cartográfica del currículo de la licenciatura citada; finalmente, también fue requerido un conocimiento mínimo o nulo acerca del método dasimétrico para asegurar una opinión más pura en la experiencia cognitiva con el método.

La edad promedio de los participantes de la prueba fue de 23.5 años, siendo 20 años la mínima registrada y 35 la máxima. Se trata entonces de un perfil de adulto joven, en últimas fases de formación para convertirse en profesionista de la Geografía.

La característica más sobresaliente de diferenciación interna de los participantes - sobre la cual se contrastarán singularidades en las experiencias cognitivas - se refiere al avance académico en sus estudios; en este sentido, $54.5 \%$ declaró haber concluido más de $90 \%$ de los créditos de la Licenciatura, $24.2 \%$ entre 80 y $90 \%$, $15.2 \%$ entre 70 y $80 \%$, y el restante $6.1 \%$ tiene menos del $70 \%$, pero el avance suficiente para cursar materias optativas.

A los participantes les fue cuestionado su interés en la Cartografía, a fin de asegurar la responsabilidad en las respuestas emitidas. En este punto, $42.4 \%$ manifestó tener un muy alto interés, $51.5 \%$ un alto interés y $6.1 \%$ un interés medio. Ninguno de los participantes registró bajo o muy bajo interés en la disciplina, por lo cual todas las entrevistas se consideraron apropiadas para este ejercicio. 


\section{Resultados en la interpretación del modelo dasimétrico}

\section{Eficacia en la identificación de signos cartográficos en diferentes clasificaciones}

Un primer punto propuesto como reflexión en la experiencia cognitiva, consistió en cerciorarse sobre la correcta identificación ${ }^{2}$ de los signos cartográficos por parte de los lectores. Como es sabido, la selección de la clasificación es perteneciente a la fase de redacción del mapa; no obstante, la correcta identificación de las clases por los usuarios puede ayudar al cartógrafo a decantarse por una clasificación u otra.

Dada la generación de 420 polígonos en el mapa dasimétrico de la densidad de población en la región analizada, pueden tomarse diversas posturas. En principio, bajo el supuesto de que es posible reconocer condiciones "muy altas", "altas", "medias", "bajas" y "muy bajas", el primer mapa dasimétrico que se puede proponer responde a esta concepción, salvo que a esas cinco clases se añade la categoría de los espacios deshabitados que evidenció el método (Figura 3).

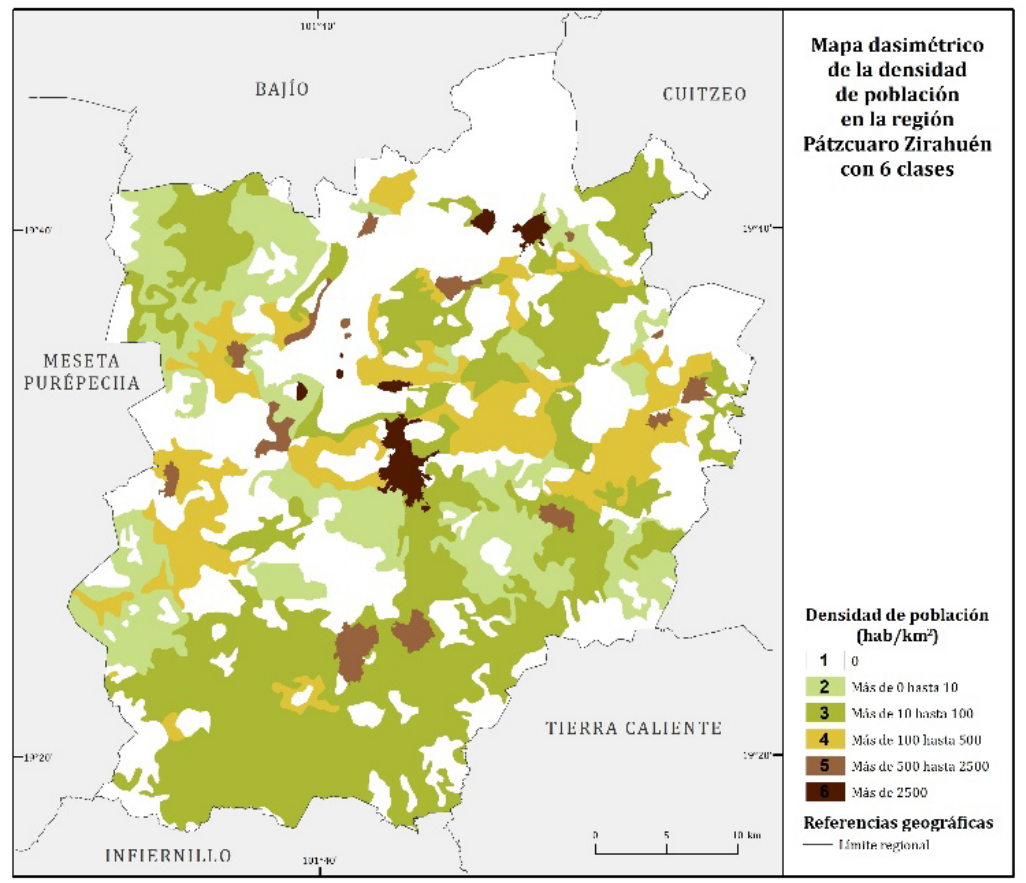

Figura 3. Muestra del modelado dasimétrico en 6 clases presentado a los entrevistados. Fuente: elaborado sobre la base de INEGI, 2010a; INEGI, 2010b; INEGI, 2013a; INEGI, 2013b; CGAP, 2016.

2 Se asume el concepto de identificación de Suavita y Flórez (1992), cuando lo reflexionan como un proceso de lectura que se considera como el más importante en el uso de mapas. 
Una segunda propuesta corresponde a una gradación más detallada derivada de la anterior, en la que se pueden reconocer condiciones "muy altas", "altas", "moderadamente altas", "medias", "moderadamente bajas", "bajas" y "muy bajas"; a estas categorías se le añaden los espacios deshabitados, lo que resulta en un mapa de 8 clases (Figura 4).

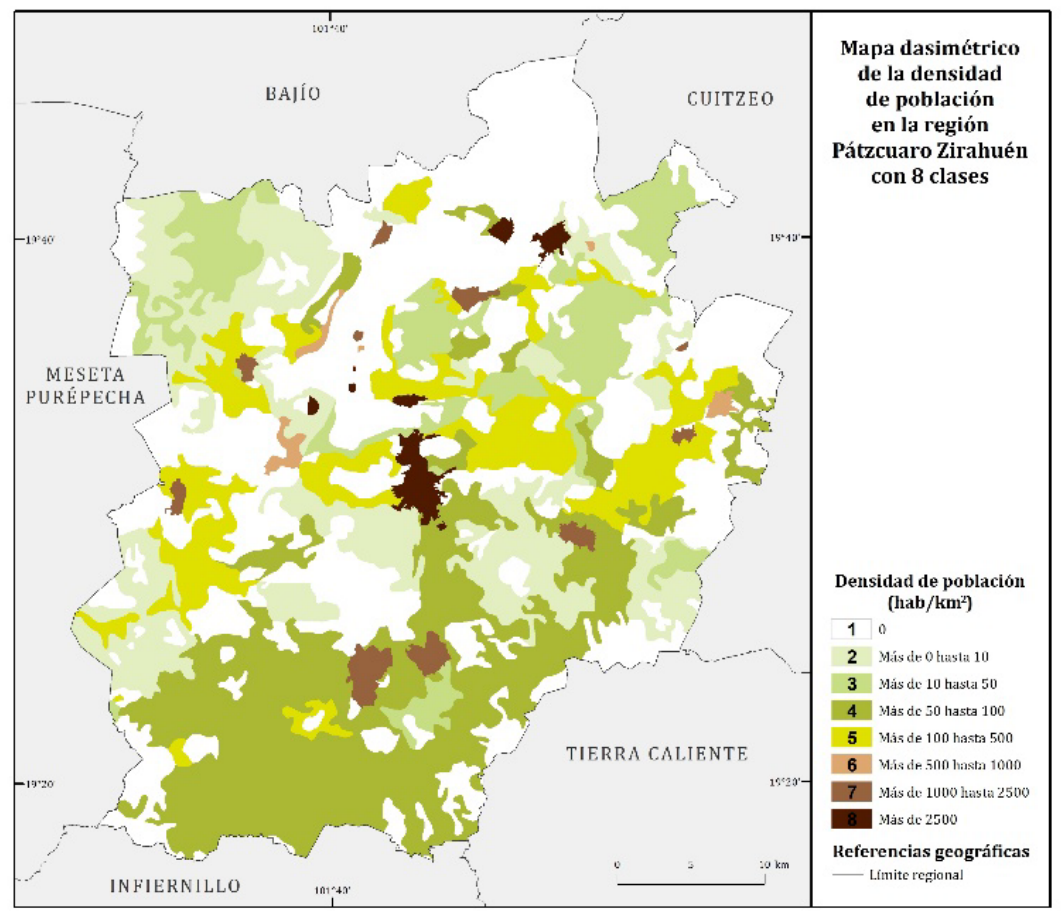

Figura 4. Muestra del modelado dasimétrico en 8 clases presentado a los entrevistados. Fuente: elaborado sobre la base de INEGI, 2010a; INEGI, 2010b; INEGI, 2013a; INEGI, 2013b; CGAP, 2016.

Una tercera alternativa puede emplear la formulación establecida por Sturges (1926; en Dent et al., 2009), basada en la fórmula: $1+3.3 \log \mathrm{N}$; donde $\mathrm{N}$ es el número de datos. En este caso, con los 420 polígonos, el número de clases es semejante a 10, y una de ellas debe destinarse a los espacios deshabitados (Figura 5).

Finalmente, una cuarta alternativa es emplear la formulación: $5 \log \mathrm{N}$ (Toyne, 1977 y Davis, 1979; en Gómez Escobar, 2004). Es reconocido que esta perspectiva brinda un mayor número de clases y, por tanto, resultaron 13 en este trabajo (Figura 6). 


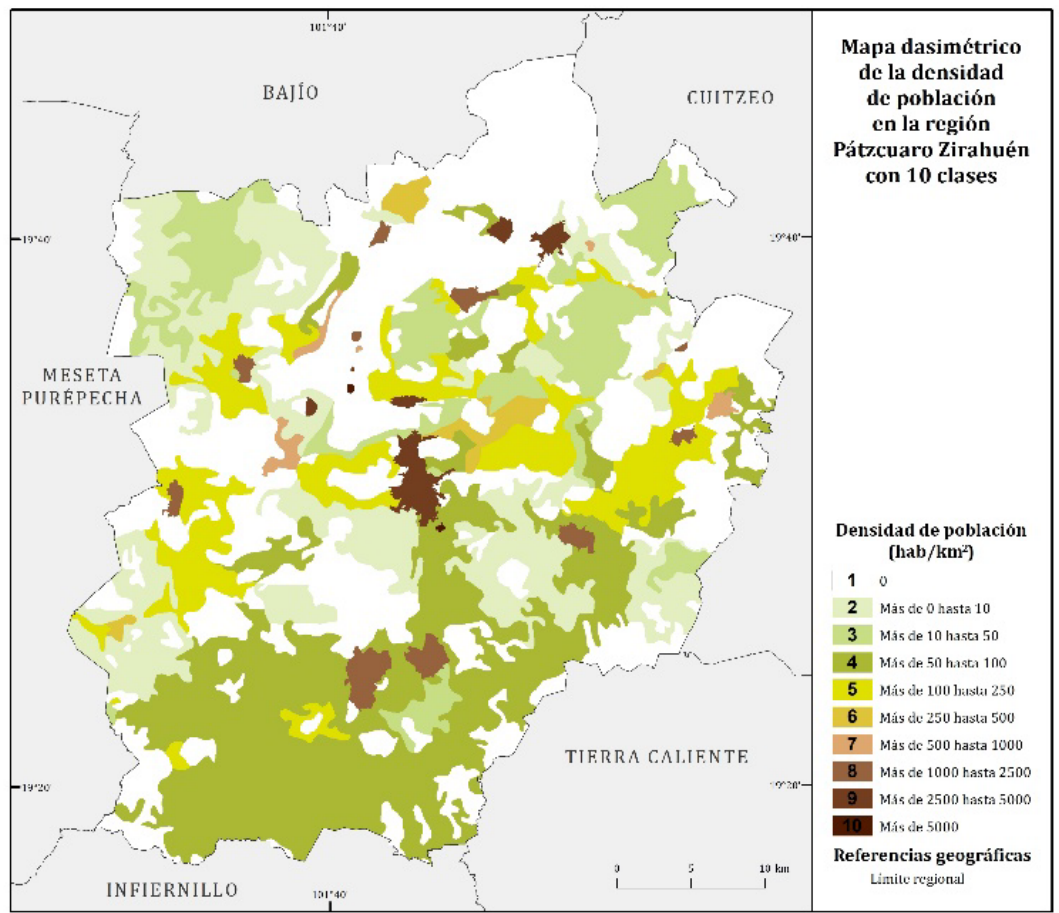

Figura 5. Muestra del modelado dasimétrico en 10 clases presentado a los entrevistados. Fuente: elaborado sobre la base de INEGI, 2010a; INEGI, 2010b; INEGI, 2013a; INEGI, 2013b; CGAP, 2016.

Cabe destacar que, para la escisión de las clases, se adoptó un criterio geométrico, debido al comportamiento estadístico de los datos; no obstante, se asumió un razonamiento cognoscitivo para ajustarlo, redondeando las cifras - como es recomendado por Brewer (2016) - y manteniendo estables algunas de ellas; con ello se pudo concentrar la interpretación de los participantes.

Las cuatro clasificaciones fueron presentadas a los entrevistados y se les solicitó lo siguiente: "En cada mapa, señala dos sitios que identifiques que pertenecen a cada rango, según el número correspondiente de la leyenda". Los resultados de identificación se contrastaron con las bases de datos originales procesadas en SIG que contienen los valores específicos de densidad de población; con ello, se pudo establecer un número de aciertos y errores de los intérpretes que se tradujo en un porcentaje de eficacia en la identificación. 


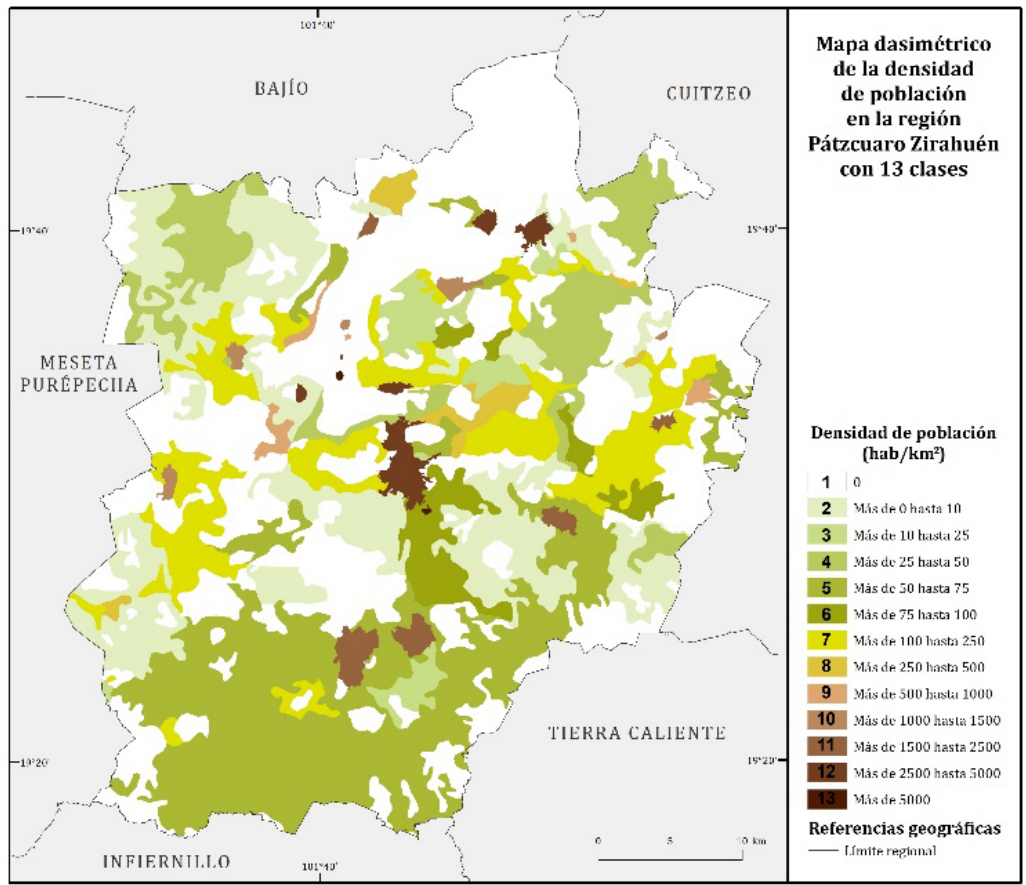

Figura 6. Muestra del modelado dasimétrico en 13 clases presentado a los entrevistados. Fuente: elaborado sobre la base de INEGI, 2010a; INEGI, 2010b; INEGI, 2013a; INEGI, 2013b; CGAP, 2016.

La Figura 7 muestra que, aunque ninguna clasificación alcanzó el 100\% de eficacia en la identificación, un menor número de clases otorga mayor porcentaje de aciertos, lo que es lógico; ahora bien, un dato relevante es que sólo dos personas pudieron acertar por completo la identificación en el modelo de 13 clases y sólo una completó los cuatro ejercicios sin fallo.

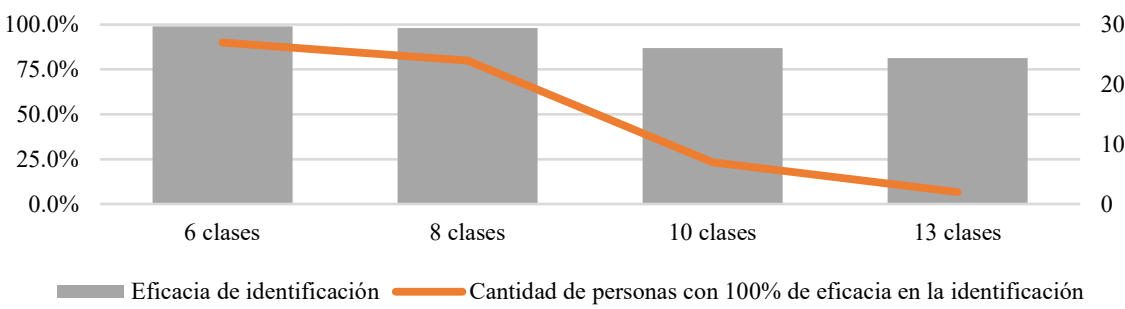

Figura 7. Eficacia en la identificación en las diferentes clasificaciones aplicadas al método dasimétrico de densidad de población.

Fuente: elaborado sobre la base de trabajo directo. 
Asimismo, existe una relación directa entre el avance académico de los participantes y su eficacia de interpretación. Aquéllos con más de 90\% de créditos, alcanzaron $94.8 \%$ de aciertos; los que poseen entre el 80 y $90 \%$ de créditos, tuvieron $87.0 \%$; los situados entre 70 y $80 \%$ de avance académico, obtuvieron una eficacia de $86.5 \%$; y los que tienen menos de $70 \%$ de avance, sólo registraron correctamente el $82 \%$ de las identificaciones solicitadas.

Complementariamente, a fin de redondear la captura de esta experiencia cognitiva, se solicitó que brindaran la opinión de la facilidad o dificultad del ejercicio anterior. Se presentaron las cinco categorías siguientes: "Muy fácil", "Fácil", "Moderado", "Difícil" y "Muy difícil" para cada clasificación presentada. La figura 8 muestra las opiniones de los participantes, donde se asignó un valor de 1 para lo considerado "Muy fácil", 2 para lo "Fácil", 3 para lo "Moderado", 4 para lo "Difícil" y 5 para lo "Muy difícil". Se aprecia que, para ellos, el modelo de 6 clases es muy fácil de interpretar y el modelo de 8 clases también se ubica en el ámbito de la facilidad; el modelo de las 10 clases presenta un considerable aumento en el esfuerzo de lectura, al ubicarse entre lo moderado y lo difícil, y el modelo de las 13 clases ronda la perspectiva de haber sido un trabajo muy difícil.

Así, en este ejercicio, existe una correlación positiva entre la eficacia de identificación y la percepción de facilidad/dificultad en la lectura de la información.

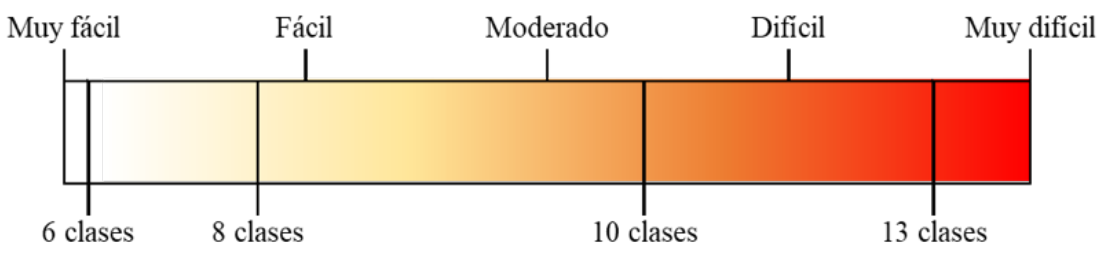

Figura 8. Perspectiva promedio de la opinión de los participantes respecto a la facilidad o dificultad de la interpretación de diferentes clasificaciones.

Fuente: elaborado sobre la base de trabajo directo.

\section{Selección del mapa dasimétrico de densidad de población y sus características}

Una vez ejecutada la identificación de las clases, resulta relevante conocer cuál de las clasificaciones sería utilizada por ellos para presentar el mapa dasimétrico de densidad de población. Sin embargo, para tomar una decisión más informada, se les presentaron tablas auxiliares con la aproximación estadística de la clasificación a la realidad, tomando en cuenta que la cantidad de población a nivel censal es de 200145 habitantes (Tablas 1-4). 
Tabla 1

Tabla auxiliar del modelo dasimétrico con 6 clases

\begin{tabular}{lccc}
\hline $\begin{array}{c}\text { Densidad de población } \\
\left(\text { hab. } /\left(\mathrm{km}^{2}\right)\right.\end{array}$ & $\begin{array}{c}\text { Densidad media } \\
\text { del rango }\end{array}$ & Area $\left(\mathrm{km}^{2}\right)$ & $\begin{array}{c}\text { Población estimada } \\
\text { por rango de densidad }\end{array}$ \\
\hline 0 & 0.00 & 656.891 & 0 \\
Más de 0 hasta 10 & 2.37 & 264.372 & 625 \\
Más de 10 hasta 100 & 46.44 & 552.448 & 25,654 \\
Más de100 hasta 500 & 190.31 & 188.843 & 35,939 \\
Más de 500 hasta 2500 & $1,274.67$ & 36.847 & 46,968 \\
Más de 2500 & $5,302.49$ & 20.495 & 108,674 \\
\hline & Total estimado por la clasificación & 217,861 \\
\hline
\end{tabular}

Fuente: elaborado con base en procesamiento en Sistema de Información Geográfica.

Tabla 2

Tabla auxiliar del modelo dasimétrico con 8 clases

\begin{tabular}{lccc}
\hline $\begin{array}{c}\text { Densidad de población } \\
\left(\text { hab. } /\left(\mathrm{km}^{2}\right)\right.\end{array}$ & $\begin{array}{c}\text { Densidad media } \\
\text { del rango }\end{array}$ & Area $\left(\mathrm{km}^{2}\right)$ & $\begin{array}{c}\text { Población estimada } \\
\text { por rango de densidad }\end{array}$ \\
\hline 0 & 0.00 & 656.891 & 0 \\
Más de 0 hasta 10 & 2.37 & 264.372 & 625 \\
Más de 10 hasta 50 & 27.07 & 165.373 & 4,476 \\
Más de 50 hasta 100 & 69.96 & 387.075 & 27,078 \\
Más de 100 hasta 500 & 190.31 & 188.843 & 35,939 \\
Más de 500 hasta 1000 & 770.15 & 10.005 & 7,706 \\
Más de 1000 hasta 2500 & $1,526.93$ & 26.842 & 40,986 \\
Más de 2500 & $5,302.49$ & 20.495 & 108,674 \\
\hline & Total estimado por la clasificación & 225,485 \\
\hline
\end{tabular}

Fuente: elaborado con base en procesamiento en Sistema de Información Geográfica.

Tabla 3

Tabla auxiliar del modelo dasimétrico con 10 clases

\begin{tabular}{lccc}
\hline $\begin{array}{c}\text { Densidad de población } \\
\text { (hab. } /\left(\mathrm{km}^{2}\right)\end{array}$ & $\begin{array}{c}\text { Densidad media } \\
\text { del rango }\end{array}$ & Area $\left(\mathrm{km}^{2}\right)$ & $\begin{array}{c}\text { Población estimada } \\
\text { por rango de densidad }\end{array}$ \\
\hline 0 & 0.00 & 656.891 & 0 \\
Más de 0 hasta 10 & 2.37 & 264.372 & 625 \\
Más de 10 hasta 50 & 26.97 & 165.373 & 4,460 \\
Más de 50 hasta 100 & 60.26 & 387.075 & 23,327 \\
Más de 100 hasta 250 & 166.97 & 167.034 & 27,889 \\
Más de 250 hasta 500 & 282.64 & 21.809 & 6,164 \\
Más de 500 hasta 1000 & 770.15 & 10.005 & 7,706 \\
Más de 1000 hasta 2500 & $1,526.93$ & 26.842 & 40,986 \\
Más de 2500 hasta 5000 & $3,506.43$ & 19.977 & 70,048 \\
Más de 5000 & $10,690.66$ & 0.518 & 5,537 \\
\hline
\end{tabular}

Fuente: elaborado con base en procesamiento en Sistema de Información Geográfica. 
Tabla 4

Tabla auxiliar del modelo dasimétrico con 13 clases

\begin{tabular}{lccc}
\hline $\begin{array}{c}\text { Densidad de población } \\
\left(\text { hab. } /\left(\mathrm{km}^{2}\right)\right.\end{array}$ & $\begin{array}{c}\text { Densidad media } \\
\text { del rango }\end{array}$ & Area $\left(\mathrm{km}^{2}\right)$ & $\begin{array}{c}\text { Población estimada } \\
\text { por rango de densidad }\end{array}$ \\
\hline 0 & 0.00 & 656.891 & 0 \\
Más de 0 hasta 10 & 2.37 & 264.372 & 625 \\
Más de 10 hasta 25 & 16.61 & 42.117 & 699 \\
Más de 25 hasta 50 & 34.39 & 123.256 & 4,239 \\
Más de 50 hasta 75 & 58.96 & 335.514 & 19,783 \\
Más de 75 hasta 100 & 89.74 & 51.561 & 4,627 \\
Más de 100 hasta 250 & 166.97 & 167.034 & 27,889 \\
Más de 250 hasta 500 & 282.64 & 21.809 & 6,164 \\
Más de 500 hasta 1000 & 770.15 & 10.005 & 7,706 \\
Más de 1000 hasta 1500 & $1,187.66$ & 7.499 & 8,906 \\
Más de 1500 hasta 2500 & $1,866.20$ & 19.343 & 36,098 \\
Más de 2500 hasta 5000 & $3,506.43$ & 19.977 & 70,048 \\
Más de 5000 & $10,690.66$ & 0.518 & 5,537 \\
\hline
\end{tabular}

Fuente: elaborado con base en procesamiento en Sistema de Información Geográfica.

De acuerdo con la pregunta "Teniendo en cuenta la facilidad/dificultad de la interpretación y la exactitud de la aproximación al resultado, ¿qué mapa consideras que es mejor para mostrar el fenómeno de la densidad de población con el método dasimétrico?", el orden de preferencias resultó el siguiente: $30.3 \%$ prefirió usar una clasificación en 6 rangos, $36.4 \%$ en 8 rangos, $24.2 \%$ en 10 rangos y 9.1 en 13 rangos. Cabe destacar que este reactivo no mostró correlación con el avance académico de los entrevistados.

Sin embargo, surge un dato interesante en este sentido. Si se compara el mapa preferido por cada participante con su eficacia de identificación respectiva en ese mapa, los que eligieron el mapa de las 6 clases alcanzaron un resultado de $98.1 \%$; los que optaron por el mapa con 8 clases registraron $97 \%$ de aciertos; un descenso se presenta en la eficacia de quienes prefirieron el de 10 clases, que en promedio alcanzaron 92\%; pero una caída acentuada se registró en el mapa de las 13 clases, que sólo obtuvo $68 \%$ de aciertos de quienes lo eligieron. Bajo estos datos, la eficacia disminuye si el número de clases aumenta, pero esto ocurre aun cuando ellos hayan considerado que podía ser mejor alternativa un mapa más detallado.

Para complementar esta respuesta, se les cuestionó acerca de la claridad en el mensaje central referente a las disparidades en la distribución de la población. Al respecto, $12.1 \%$ manifestó que el mensaje es claro independientemente de la clasificación utilizada, pero la gran mayoría - 75.8\% - eligió alguna clasificación como la de mayor aporte al mensaje central. En este sentido, 39.3\% de ellos afirmó que el mensaje central quedaba clarificado usando la clasificación en 6 rangos, $35.7 \%$ en 8 
rangos y $14.3 \%$ en 10 rangos y $10.7 \%$ en 13 rangos. Ahora bien, $6.1 \%$ consideró que el método dasimétrico no es adecuado para mandar un mensaje claro respecto a las diferencias en la distribución de la población.

Es así que puede juzgarse que el mapa con seis clases resultó el más asertivo para el grupo de intérpretes, no sólo porque para ellos resulta muy claro en el mensaje central, sino también porque prácticamente no presentó fallos en la identificación de signos y presenta la lectura más fácil. No obstante, para diseñar el mapa dasimétrico que mostrara la distribución de la población, fue importante conocer si presentarían la tabla auxiliar para una extracción mayor de la información, pero donde también se reflejaría la aproximación del método. Bajo el cuestionamiento “¿Colocarías en el mapa las tablas auxiliares para una mayor extracción de información?”, 72.7\% se manifestó a favor y $27.3 \%$ en contra. Con ello, se redondea la experiencia cognitiva referente al diseño y presentación del mapa dasimétrico más adecuado para este perfil de usuario (Figura 9).

\section{Obtención de información con la variable relacionada}

Debido a que el método dasimétrico hace uso de una información auxiliar relacionada - en este caso la de vegetación y uso del suelo — es importante conocer si los intérpretes podían obtener información adicional, producto de la integración de las coberturas; de esta manera, les fue presentado el mapa de vegetación y uso del suelo de la región (Figura 2).

Con esta base, se les solicitó lo siguiente: "En el mapa que hayas considerado como el mejor, coloca una letra $\mathrm{A}$ a tres áreas agrícolas, una letra $\mathrm{B}$ a tres áreas de bosques y una letra $\mathrm{C}$ a los cuerpos de agua". Estos ejercicios se contrastaron con los usos de suelo registrados en las bases de datos procesadas en SIG, resultando una eficacia de identificación de $89.3 \%$ para las áreas agrícolas, 90.7\% para los bosques de y $95.5 \%$ para los cuerpos de agua.

Avanzando en la profundidad de la lectura del mapa, se les cuestionó “¿Qué densidad media le asignarías a las áreas agrícolas, a los bosques y a las zonas urbanas?". Un primer paso en este reactivo es poder caracterizar, en un nivel ordenado, los espacios de mayor densidad, los situados en el medio y los de menor densidad. En este contexto, $72.7 \%$ de los participantes pudo distinguir el orden adecuado en la zona de estudio, donde los espacios urbanos son los más densamente poblados, seguidos por los agrícolas y después los bosques.

Es relevante destacar que, en esta fase de la entrevista, sí existe una relación directa entre el avance académico de los entrevistados y la distinción del orden adecuado de las densidades en los espacios urbanos, agrícolas y forestales, siendo que se obtiene mayor cantidad de aciertos cuanto mayor es el avance académico (Figura 10). 


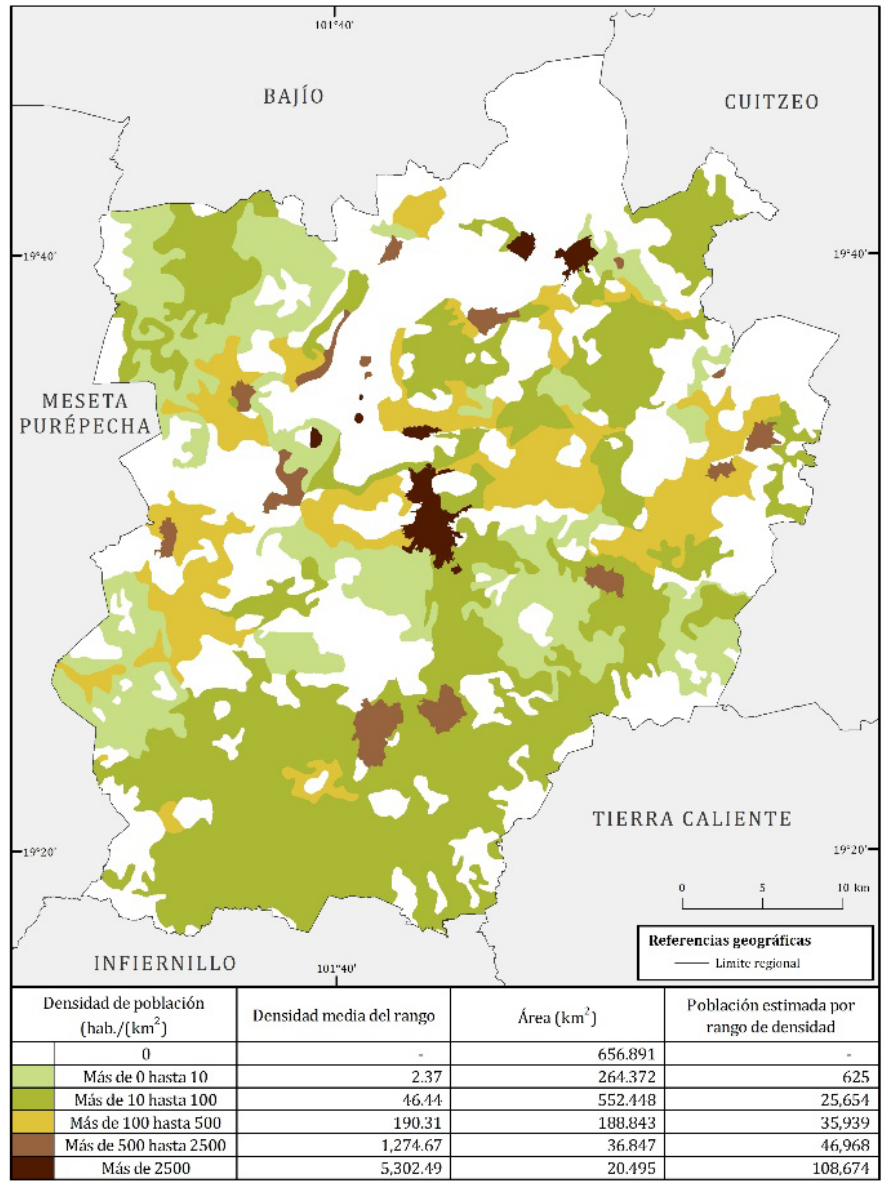

Figura 9. Mapa dasimétrico con 6 clases de densidad de población en la región Pátzcuaro Zirahuén.

Fuente: elaborado sobre la base de INEGI, 2010a; INEGI, 2010b; INEGI, 2013a; INEGI, 2013b; CGAP, 2016.

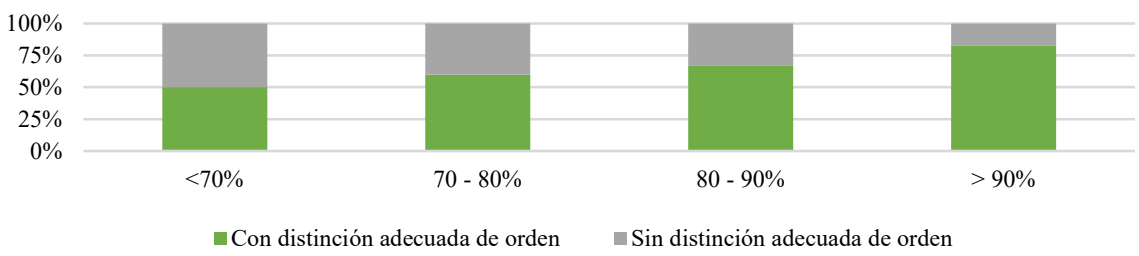

Figura 10. Logros de distinción adecuada del orden de densidades de población según avance académico de los entrevistados.

Fuente: elaborado sobre la base de trabajo directo. 
Desde el punto de vista cuantitativo del fenómeno, todos los participantes otorgaron cifras de densidad para los tres diferentes espacios solicitados. Mediante un promedio de los datos, atribuyeron $1937 \mathrm{hab} / \mathrm{km}^{2}$ a las zonas urbanas, $98 \mathrm{hab} / \mathrm{km}^{2}$ a las áreas agrícolas y $49 \mathrm{hab} / \mathrm{km}^{2}$ a los bosques. Es importante señalar que estas cifras promedio provienen de consideraciones ampliamente variables; por esta razón, es relevante analizar cuántos de ellos se aproximaron a una cifra de $\pm 25 \%$ de error, siendo las cifras reales promedio de la zona $2445 \mathrm{hab} / \mathrm{km}^{2}$ para las zonas urbanas, $88 \mathrm{hab} / \mathrm{km}^{2}$ para las áreas agrícolas y $7 \mathrm{hab} / \mathrm{km}^{2}$ para los bosques. Bajo este criterio, sólo dos personas — que corresponden al $6.1 \%$ de los entrevistados - lograron acercarse a las tres cifras promedio dentro del margen de error, $24.2 \%$ tuvieron dos aproximaciones adecuadas, 33.3\% una aproximación adecuada y 36.4\% salieron del margen de error en todos los casos.

En este contexto, vinculando el entendimiento cualitativo-ordenado del fenómeno y la exactitud cuantitativa dada por el número de aproximaciones adecuadas, se puede figurar, en un esquema bi-conformado, el acercamiento a la comprensión del fenómeno de la densidad de población con el mapa dasimétrico, donde la cercanía hacia el segmento superior derecho refleja la mejor apropiación (Figura 11).

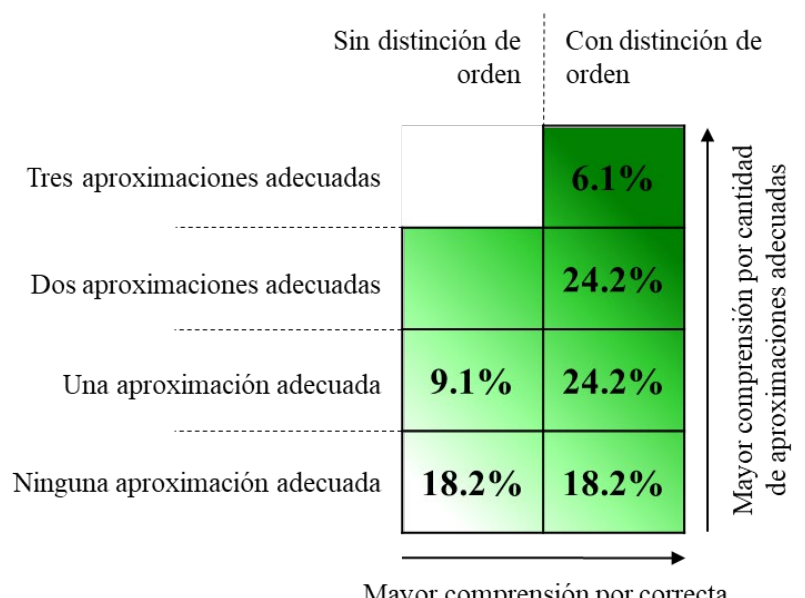

Mayor comprensión por correcta interpretación cualitativa del fenómeno

Figura 11. Comprensión del fenómeno de la densidad de población en la región Pátzcuaro Zirahuén mediante la conjunción de las interpretaciones cualitativas y cuantitativas.

Fuente: elaborado sobre la base de trabajo directo.

En un último alcance de la relación de información —el más demandante, dado que se asocia con el proceso de la inducción cartográfica o la extensión del contenido 
del mapa - se solicitó proporcionar una cifra de porcentaje de habitantes en las tres coberturas de uso del suelo y vegetación; específicamente se cuestionó: "Si las áreas agrícolas ocupan $773.1 \mathrm{~km}^{2}$, los bosques $676.4 \mathrm{~km}^{2}$ y las zonas urbanas $48.2 \mathrm{~km}^{2}$, ¿podrías acercarte a calcular la proporción de población que vive en esos usos de suelo?". Cabe destacar que, en este reactivo, $45.5 \%$ de los entrevistados rehusaron responder, bajo el argumento de no tener la cifra total absoluta, partir de datos clasificados o desconocer el procedimiento para obtener el resultado; lo cierto es que la cifra censal de 200145 habitantes en la región sí fue proporcionada, e incluso se mostraron las cifras calculadas de acuerdo con el modelo de clasificación; también resulta cierto que los entrevistados debían de partir de comportamientos medios de densidad para poder dar un resultado. No obstante, más allá de requerir cifras precisas, lo relevante es conocer los diferentes alcances de los intérpretes y la medida en que se puede llegar a una imagen más completa del fenómeno cartografiado.

Así, 48.5\% $\%^{3}$ de los entrevistados que tomó la alternativa de proporcionar cifras, consiguieron, en general, una impresión adecuada del fenómeno; de ellos, 81.3\% identificó adecuadamente que la mayor proporción de población vive en ámbitos urbanos, seguidos por las áreas agrícolas y los bosques (Figura 12).

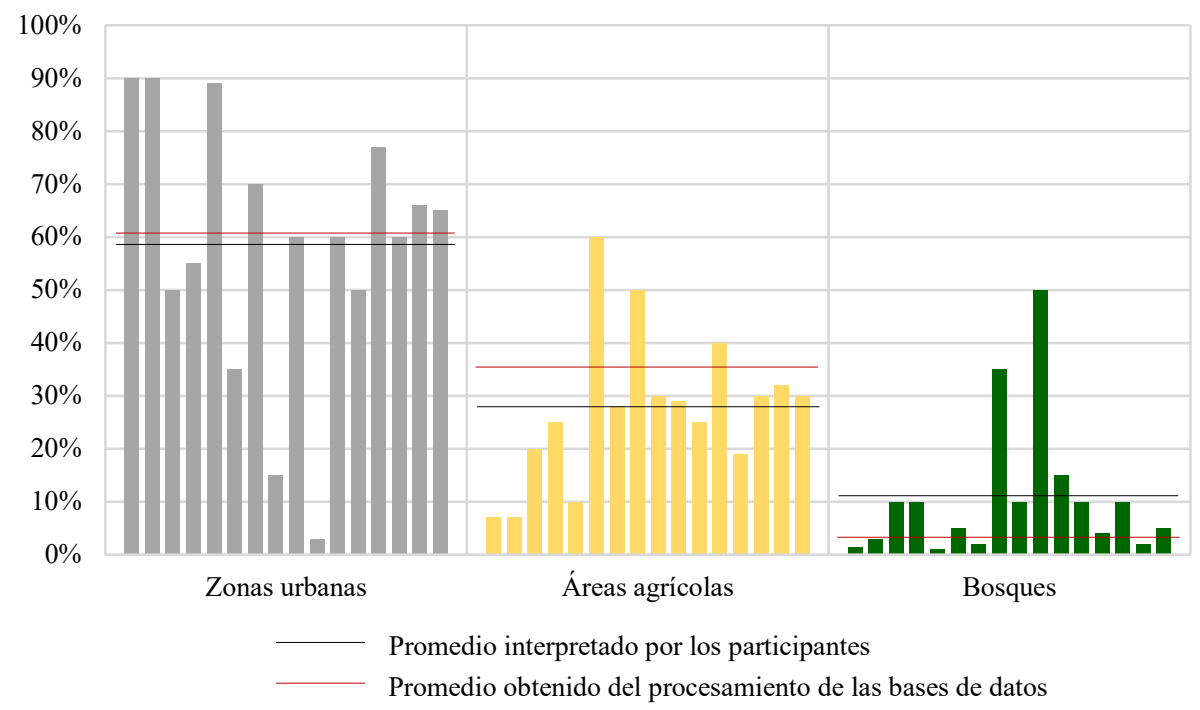

Figura 12. Perspectiva interpretativa de los participantes referente al porcentaje de población que habita en distintos usos de suelo.

Fuente: elaborado sobre la base de trabajo directo.

3 Dos entrevistas fueron eliminadas en este reactivo por resultar incomprensibles para su registro. 


\section{Perspectiva de uso del método dasimétrico}

Trascendiendo la región de estudio, a la pregunta: “¿Consideras que el método dasimétrico es adecuado para modelar la densidad de población?", 78.8\% de los participantes contestó afirmativamente. Más allá de la interpretación del fenómeno, ahondando en la posibilidad de uso del método por parte de los entrevistados, al cuestionar: "En tus trabajos, ¿usarías el método dasimétrico para expresar la densidad de población?”, 87.9\% se manifestó a favor. Por su parte, cuando se preguntó: “¿El método te inspira a pensar en otras relaciones espaciales para mostrar un comportamiento distinto del fenómeno a nivel cuantitativo?", 97.0\% de los entrevistados respondió en sentido positivo. De estas respuestas se extrae que es el método dasimétrico el que captura la atención; el fenómeno — la densidad de poblaciónacopia, relativamente, menos interés de los participantes.

\section{Reflexiones en torno al método dasimétrico}

La relevancia de haber interactuado con personas con escaso o nulo contacto con el método dasimétrico tiene relevancia en este punto, ya que puede dar una opinión más pura de la apreciación del método. En esta fase de la entrevista, se optó por un reactivo de respuesta abierta que les permitiera expresar más libremente sus opiniones. En estos textos pueden apreciarse cinco tipos de reflexiones diferenciados en torno al método, pero no excluyentes entre sí: aprehensión general, cualidades percibidas, restricciones percibidas, interés académico-cartográfico y temáticas de aplicación. A través de la técnica gráfica de la nube de conceptos, es posible brindar una idea de la experiencia obtenida a través de la interacción con método dasimétrico (Figura 10).

En las expresiones de aprehensión general, los intérpretes se abocan a caracterizar lo recientemente conocido desde la posición más amplia; se trata de posiciones neutrales o ligeramente positivas, pero de las que deriva una explicación de la apreciación. En cuanto la percepción de las cualidades, los intérpretes evalúan los aportes que les brinda el método y, de forma natural, surgen expresiones positivas. Por su parte, en lo referente a las restricciones percibidas, los intérpretes suelen conjeturar las situaciones en las que el método no se aplicaría y las dificultades que enfrentaron durante la interacción. El interés académico-cartográfico queda evidenciado cuando los intérpretes deducen el sentido abstracto que puede tener la aplicación del método. Finalmente, en las temáticas de aplicación, visualizan la concreción en función de las posibilidades temáticas vislumbradas.

\section{Discusión}

Dado el perfil de los participantes, se tienen bases para sustentar que el modelo de las 10 clases presenta un buen porcentaje de eficacia en la identificación de los signos cartográficos y, al mismo tiempo, presenta una adecuada aproximación a la realidad 


\begin{tabular}{|c|c|}
\hline 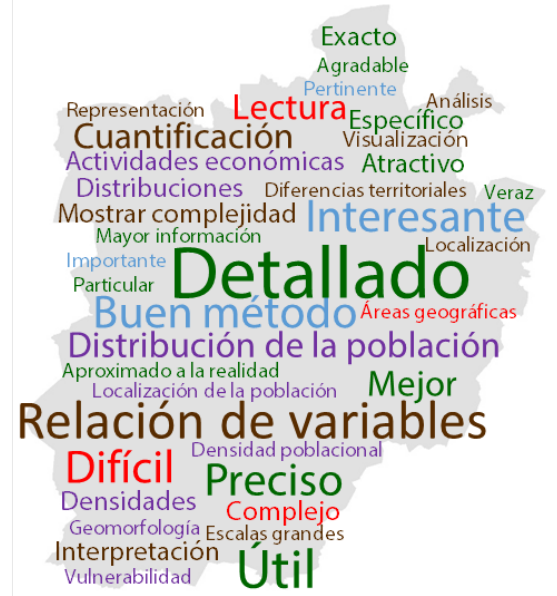 & 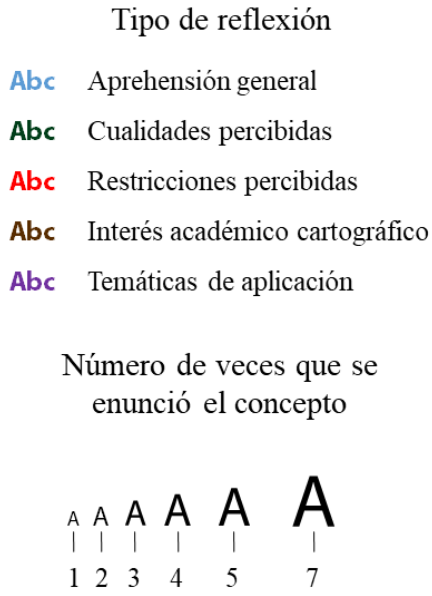 \\
\hline
\end{tabular}

Figura 10. Tipos de reflexiones derivadas de la lectura del mapa con empleo del mapa dasimétrico.

Fuente: elaborado sobre la base de trabajo directo.

geográfica, contabilizando al 93.3\% de la población censada; además, resultó suficientemente retador en su lectura. No obstante, comúnmente el intérprete desea asegurarse de haber realizado una identificación sin fallo; ésta es, posiblemente, la razón por la cual la mayoría de ellos eligieron los mapas con 6 y 8 clases.

No se considera que en esta selección haya influido el uso de las variables visuales de los mapas presentados, ya que se optó por tres diferentes matices de colores, jerárquicamente secuenciados en el espectro electromagnético (verde-amarillonaranja) y potenciados por la variable visual de valor, que es correspondiente con la naturaleza cuantitativa de la información del mapa y podría otorgar hasta seis diferencias distintas por cada matiz de color, como lo advierten Monmonier (1996), Gómez Escobar (2004) y Tyner (2010). Por su parte, Brewer (2016) advierte el decremento en la capacidad de discernir colores al incrementarse el número de clases, por ello también considera que, cuando las clases se incrementan, deben existir transiciones en el matiz, y no sólo en la luminosidad, tal como se hizo en este ejercicio.

La generación de una gran cantidad de polígonos que podrían permitir un menor grado de generalización en las clases y la diferencia estadística más pequeña en la aproximación del modelo a la realidad, no es necesariamente el mejor camino al momento en que interviene la interpretación humana. Este trabajo demostró que la eficacia en la identificación del $81 \%$ de los signos en el mapa de 13 clases diluye el mensaje central en la mente de los intérpretes e, incluso, podría tener impactos ante un eventual recuento de población siguiendo sus interpretaciones. 
Para el grupo entrevistado, el método se reveló como una alternativa satisfactoria para cartografiar con mayor detalle y naturalidad el comportamiento de información en espacios de poca o nula subdivisión político-administrativa; en este sentido, se razonó especialmente útil para estudios a escala municipal y microrregional. Sin embargo, no debe considerarse que el método es exclusivo de escalas medias y grandes; podría aplicarse en espacios geográficos de mayor amplitud que impliquen una escala más pequeña; el requerimiento es hacer uso de información auxiliar para modelar los procesos, y que esta información se presente con una generalización apropiada a la escala cartográfica elegida.

Los participantes pudieron distinguir, de forma empírica, con base en sus conceptos sobre Cartografía, algunas de las cualidades del método dasimétrico. Al caracterizarlo como "detallado", "preciso", incluso como "complejo", o que tiene como finalidad la "relación de variables", puede considerarse que manifestaron sintonía con las definiciones de Robinson et al., (1987: 346) cuando refieren que "Mediante la subdivisión de unidades de áreas estadísticas originales, puede añadirse detalle adicional a la presentación en base a cualquier conocimiento que el cartógrafo tenga acerca de los datos [...]"; o cuando DeMers (2005: 283) reflexiona que "El cartografiado dasimétrico intenta romper las estructuras artificiales para desenmascarar las estructuras escondidas". Con ello, se deduce que el método, por sí mismo, emite mensajes contundentes de sus características principales; dentro de ellas, la dificultad que implica su concepción académica.

\section{Conclusiones}

Si bien, en este trabajo, los participantes entrevistados fueron sustancialmente concebidos como usuarios - lectores - de un mapa dasimétrico, puede reconocerse que también subyacía la perspectiva de ser modeladores y propagadores del método; por esta causa, el trabajo hace uso de materiales y técnicas a su alcance. Particularmente, los materiales están puestos a disposición gratuita y “en línea” por el principal organismo responsable de la información cartográfica en México, que es el INEGI; asimismo, los procedimientos en SIG para la obtención del mapa dasimétrico no son ajenos a lo que pueden ejecutar.

Este estudio revela que los entrevistados, como usuarios del método, pudieron obtener una lectura apropiada del mapa dasimétrico; sin embargo, su gusto y logros en la lectura son ligeramente tendientes hacia los niveles menos detallados. Ahora bien, es posible pensar que las generaciones recientes de geógrafos interesados en la Cartografía desean mensajes más rápidos y contundentes en los mapas.

En este sentido, es posible afirmar que la Cartografía debe fomentar la continua evaluación de sus propuestas y modelos; si se toma en cuenta el hecho de que el ser 
humano cambia en el tiempo las formas de comunicarse y de comprender los mensajes; entonces, la Cartografía, como medio de comunicación, también debe entender continuamente los requerimientos y habilidades del intérprete.

El hecho de tomar en cuenta las experiencias cognitivas tiene sentido en las etapas de evaluación y retroalimentación cartográfica; el cartógrafo puede desapegarse de la imposición en la modelación de los fenómenos y tomar en cuenta las necesidades y conocimientos del intérprete; sin embargo, también cabe la posibilidad de hacer un balance. Aun cuando es cierto que los estudios de cognición aplicados a los mapas se formulan para conocer al usuario, y éste manifestará una inclinación o gusto por una representación, también hay que evaluar sus habilidades de interpretación. En tanto ambos resultados sean positivos, se puede escoger entre la visión del usuario o la del cartógrafo; empero, si hay experiencias de identificación poco exitosas por parte del usuario, debe privilegiarse el mejor resultado en la lectura.

Si bien es necesario seguir postulando estrategias para la captura de experiencias cognitivas, las recopiladas en este trabajo reafirman que la Cartografía no es sólo técnica aplicada; las posibilidades de interpretación y de presentación de la información, restringen las soluciones técnicas que puedan ofrecerse.

\section{Agradecimientos}

Trabajo realizado con el apoyo del Programa UNAM-DGAPA-PAPIME. Proyecto PE304418 "Contribución de las perspectivas temática y matemática en las experiencias cartográficas actuales".

Se agradece, asimismo, la participación comprometida de los estudiantes de la licenciatura en Geografía de la Universidad Nacional Autónoma de México.

\section{Bibliografía}

Brewer, C. (2016). Designing Better Maps. A guide for GIS Users, ESRI Press, United States of America, $231 \mathrm{pp}$.

CGAP (2016). Región VII Pátzcuaro Zirahuén, Coordinación General de Gabinete y Planeación, Gobierno del Estado de Michoacán <http://publicadorlaip.michoacan.gob.mx/itdif/2017/71/Caracterizacion\%20Regional\%20Patzcuaro\%20Zirahuen.pdf $>$, consultado en mayo 2018.

DeMers, M.N. (2005). Fundamentals of Geographic Information Systems, Wiley, New York, 468 pp.

Dent, B.D.; J.S. Torguson and T.W. Holder (2009). Cartography: thematic map design, McGraw-Hill, USA, 336 pp.

Díaz-Bravo, L.; U. Torruco-García; M. Martínez-Hernández; M. Varela-Ruiz (2013). "La entrevista, recurso flexible y dinámico", Investigación en Educación Médica, núm. 7, Universidad Nacional Autónoma de México, México, pp. 162-167. 
DiBiase, D. (1990). "Visualization in the Earth Sciences", Earth and Mineral Sciences Bulletin, 59(2), The Pennsylvania State University, Pennsylvania, pp. 1318.

Eckert, M. (1961). Cartografia, Unión Tipográfica Editorial Hispano Americana, México, $162 \mathrm{pp}$.

Eicher, C. and Brewer, C. (2001). "Dasymetric Mapping and Areal Interpolation: Implementation and Evaluation", Cartography and Geographic Information Science, 28(2), Taylor \& Francis, UK, pp. 125-138.

Gómez Escobar, M.C. (2004). Métodos y técnicas de la Cartografía Temática, Instituto de Geografía, Universidad Nacional Autónoma de México, México, 175 pp.

INEGI (2010a). Censo de Población y Vivienda 2010: Principales resultados por localidad (ITER), México, < http://www.inegi.org.mx/est/contenidos/proyectos/ ccpv/cpv2010/iter_2010.aspx>, consultado en mayo 2018.

(2010b). Marco geoestadístico 2010 versión 5.0, Instituto Nacional de Geografía y Estadística, México, <http://www.beta.inegi.org.mx/app/biblioteca/ ficha.html?upc=702825292812>; consultado en mayo 2018 .

(2013a). Conjunto de datos vectoriales de la carta de Uso del suelo y vegetación. Escala 1:250 000. Serie V (Continuo Nacional) Morelia, México $<$ http://www.beta.inegi.org.mx/app/biblioteca/ficha.html?upc=702825568580>; consultado en mayo 2018.

- (2013b). Marco geoestadístico 2013 versión 6.0, México $<$ http://www.beta.inegi.org.mx/app/biblioteca/ficha.html?upc=702825292829>; consultado en mayo 2018.

(2017). Marco Geoestadístico, junio 2017, México $<$ http://www.beta.inegi.org.mx/app/biblioteca/ficha.html?upc=889463142683>; consultado en mayo 2018.

Jameson, F. (1991). La lógica cultural del capitalismo tardío, Paidós, Barcelona, 121 pp.

Joly, F. (1979). La Cartografia, Ariel, Barcelona, 280 pp.

Lynch, K. (1960). The image of the city, The MIT Press, U.S.A., 194 pp.

MacEachren, A. (1994). "Visualization in Modern Cartography: Setting the agenda" in MacEachren, A.; D.R. Fraser Taylor (eds.) Visualization in Modern Cartography, Elsevier, Oxford, UK, pp. 1-12.

Martínez, P. (2006). "El método de estudio de caso. Estrategia metodológica de la investigación científica”, Pensamiento y gestión, núm. 20, Universidad del Norte, Barranquilla, Colombia, pp. 165-193.

Mennis, J.; Hultgren, T. (2006). “Intelligent Dasymetric Mapping and Its Application to Areal Interpolation", Cartography and Geographic Information Science, 33(3), Taylor \& Francis, UK, pp. 179-194. 
Monmonier (1996). How to lie with maps, The University of Chicago Press, Chicago, $207 \mathrm{pp}$.

Montello, D. (2002). "Cognitive Map-Design Research in the Twentieth Century: Theoretical and Empirical Approaches", Cartography and Geographic Information Science, 29(3), Taylor \& Francis, UK, pp. 283-304.

Neves, O.; J. Strauch and C. Ajara (2017). "Dasymetric methods applied to Jacarepaguá watershed", Bulletin of Geodetic Sciences, 23(4), Universidade Federal do Paraná, Paraná, Brasil, pp. 606-622. DOI: 10.1590/s1982-21702017000400040.

Raisz, E. (1948). General Cartography, McGraw Hill, New York, 254 pp.

Robinson, A.H.; R.D. Sale; J.L. Morrison y P.C. Muehrcke (1987). Elementos de Cartografía, Omega, Barcelona, 543 pp.

Sleeter, R. (2013). "Dasymetric mapping techniques for the San Francisco Bay region, California", Urban and Regional Information Systems Association, Annual Conference Proceedings, Des Plaines, Illinois, 12 pp.

Suavita, M. y A. Flórez (1992). "La percepción y la comprensión en Cartografía Temática", Revista Cartográfica, núm. 61, Instituto Panamericano de Geografía e Historia, México, pp. 105-130.

Tapp, A.F. (2010). “Areal Interpolation and Dasymetric Mapping Methods Using Local Ancillary Data Sources", Cartography and Geographic Information Science, 37(3), Taylor \& Francis, UK, pp. 215-228.

Tyner, J. (2010). Principles of map design, The Guilford Press, New York, 258 pp.

Wood, D. (1992). The Power of Maps, The Guilford Press, New York, 248 pp. 